\title{
Dietary magnesium, calcium:magnesium ratio and risk of reflux oesophagitis, Barrett's oesophagus and oesophageal adenocarcinoma: a population-based case-control study
}

\author{
Qi Dai ${ }^{1}$, Marie M. Cantwell ${ }^{2}$, Liam J. Murray ${ }^{2}$, Wei Zheng ${ }^{1}$, Lesley A. Anderson ${ }^{2}$ and Helen G. Coleman ${ }^{2 *}$ \\ on behalf of the FINBAR study group \\ ${ }^{1}$ Vanderbilt Epidemiology Center, Department of Medicine, Vanderbilt-Ingram Cancer Center, Vanderbilt University School of \\ Medicine, Nashville, TN 37203, USA \\ ${ }^{2}$ Cancer Epidemiology \& Health Services Research Group, Centre of Excellence for Public Health Northern Ireland, Centre for \\ Public Health, Queens University Belfast, Belfast, BT12 6BJ, Northern Ireland
}

(Submitted 28 July 2015 - Final revision received 6 October 2015 - Accepted 9 October 2015 - First published online 13 November 2015)

\section{Abstract}

Evidence suggests a role of $\mathrm{Mg}$ and the ratio of $\mathrm{Ca}: \mathrm{Mg}$ intakes in the prevention of colonic carcinogenesis. The association between these nutrients and oesophageal adenocarcinoma - a tumour with increasing incidence in developed countries and poor survival rates - has yet to be explored. The aim of this investigation was to explore the association between $\mathrm{Mg}$ intake and related nutrients and risk of oesophageal adenocarcinoma and its precursor conditions, Barrett's oesophagus and reflux oesophagitis. This analysis included cases of oesophageal adenocarcinoma ( $n$ 218), Barrett's oesophagus ( $n$ 212), reflux oesophagitis ( $n$ 208) and population-based controls $(n 252)$ recruited between 2002 and 2005 throughout the island of Ireland. All the subjects completed a 101-item FFQ. Unconditional logistic regression analysis was applied to determine odds of disease according to dietary intakes of $\mathrm{Mg}$, Ca and $\mathrm{Ca}: \mathrm{Mg}$ ratio. After adjustment for potential confounders, individuals consuming the highest amounts of $\mathrm{Mg}$ from foods had significant reductions in the odds of reflux oesophagitis (OR 0.31 ; $95 \% \mathrm{CI}$ $0 \cdot 11,0.87$ ) and Barrett's oesophagus (OR 0.29; $95 \%$ CI 0.12, 0.71) compared with individuals consuming the lowest amounts of Mg. The protective effect of $\mathrm{Mg}$ was more apparent in the context of a low Ca:Mg intake ratio. No significant associations were observed for $\mathrm{Mg}$ intake and oesophageal adenocarcinoma risk (OR 0.77; 95\% CI 0.30, 1.99 comparing the highest and the lowest tertiles of consumption). In conclusion, dietary $\mathrm{Mg}$ intakes were inversely associated with reflux oesophagitis and Barrett's oesophagus risk in this Irish population.

\section{Key words: Diets: Magnesium: Calcium: Vitamin D: Reflux oesophagitis: Barrett's oesophagus: Oesophageal adenocarcinoma}

$\mathrm{Mg}$, the most abundant intracellular divalent cation in the body, plays an essential role in over 300 biological activities $^{(1-6)}$. The major food sources of $\mathrm{Mg}$ are whole-grain foods, nuts, legumes, green leafy vegetables and deep-ocean fish ${ }^{(7)}$. Epidemiological studies have found low $\mathrm{Mg}$ intake to be related to an elevated risk of colorectal neoplasia in some ${ }^{(8-11)}$ but not all studies $^{(12-14)}$. One potential explanation for the inconsistency is that the interaction between $\mathrm{Mg}$ and $\mathrm{Ca}$ was not considered. Several studies have suggested that $\mathrm{Ca}$ and $\mathrm{Mg}$ may directly or indirectly compete for intestinal absorption ${ }^{(15,16)}$. Over $80 \%$ of plasma $\mathrm{Mg}$ is ultrafiltrated and reabsorbed in the kidneys. A high $\mathrm{Ca}$ intake consistently leads to significantly increased excretion of $\mathrm{Mg}$ via urine $\mathrm{e}^{(17-21)}$. Thus, it is possible that longterm consumption of a high $\mathrm{Ca}: \mathrm{Mg}$ ratio diet may lead to $\mathrm{Mg}$ deficiency, even in the context of adequate $\mathrm{Mg}$ intake ${ }^{(22)}$.

We have reported that only when individuals consume diets with low $\mathrm{Ca}: \mathrm{Mg}$ ratios (i.e. below median ratios between 2.6 and 2.8) intakes of $\mathrm{Ca}$ and $\mathrm{Mg}$ may be related to a reduced risk of colorectal adenoma ${ }^{(8)}$, and Ca supplementation led to a reduced risk of adenoma recurrence in one randomised clinical trial $^{(23)}$. Further, Ca:Mg intake ratios modified the associations of dietary intakes of $\mathrm{Mg}$ and $\mathrm{Ca}$ and risks of mortality due to cancer and CVD in two large-scale population-based cohort studies conducted in Chinese populations with very low (median ratio of 1.7$) \mathrm{Ca}: \mathrm{Mg}$ ratios $^{(24)}$. Very recently, we reported potential interactions between dietary $\mathrm{Mg}$ with dietary vitamin $\mathrm{D}$ and serum 25-hydroxyvitamin $\mathrm{D}^{(25)}$.

Previous findings from our Irish population-based case-control study found no association between Ca intake and risk of oesophageal adenocarcinoma, Barrett's oesophagus or reflux oesophagitis, whereas high vitamin D intakes were unexpectedly associated with an increased risk of oesophageal adenocarcinoma $^{(26)}$. Given the emerging evidence of $\mathrm{Mg}$ as a chemopreventive dietary agent for colorectal neoplasia described above, and its intrinsic relationship with $\mathrm{Ca}^{(8,15-24)}$ and vitamin $\mathrm{D}^{(25)}$, we hypothesised that the previously observed associations for $\mathrm{Ca}$ and vitamin $\mathrm{D}$ intake may differ according to $\mathrm{Mg}$ intake. Furthermore, to our knowledge, no

* Corresponding author: Dr H. G. Coleman, fax +44 2890 235900, email h.coleman@qub.ac.uk 
study to date has investigated $\mathrm{Mg}$ intake in relation to risk of these oesophageal disorders. Identifying potential risk factors for oesophageal adenocarcinoma is of strong public health relevance, given its rising incidence in Western populations and associated poor survival rates ${ }^{(27,28)}$. Differences in the prevalence of oesophageal cancer and gastro-oesophageal reflux disease between Eastern and Western populations lend further support to dietary risk factors potentially contributing to their aetiology ${ }^{(29,30)}$. Gastro-oesophageal reflux is a major risk factor for oesophageal adenocarcinoma and medications commonly used to treat reflux symptoms, such as proton pump inhibitors $^{(31)}$, may lead to Mg deficiency ${ }^{(32,33)}$. Therefore, it may be even more pertinent to intervene to achieve optimal $\mathrm{Mg}$ intakes in this patient group.

The primary aim of this investigation was to evaluate the association between $\mathrm{Mg}$ intake and risk of reflux oesophagitis, Barrett's oesophagus and oesophageal adenocarcinoma. Secondary aims of this study were to evaluate the associations between intakes of the inter-related nutrients of $\mathrm{Mg}$, $\mathrm{Ca}$ and vitamin $\mathrm{D}$ according to $\mathrm{Ca}: \mathrm{Mg}$ intake ratios and the risk of oesophageal lesions.

\section{Methods}

\section{Study design}

Study participants were drawn from the Factors INfluencing the Barrett's Adenocarcinoma Relationship study, an all-Ireland population-based case-control study established to investigate the aetiology of reflux oesophagitis, Barrett's oesophagus and oesophageal adenocarcinoma ${ }^{(34-36)}$. In brief, incident cases of oesophageal adenocarcinoma ( $n$ 227), long-segment Barrett's oesophagus ( $n$ 224) and population controls ( $n$ 260) were recruited from Northern Ireland and the Republic of Ireland between March 2002 and July 2004. Reflux oesophagitis cases ( $n$ 230) were recruited from Northern Ireland only between 2004 and 2005. Barrett's oesophagus, reflux oesophagitis and control subjects were frequency-matched within 5-year age and sex strata to oesophageal adenocarcinoma cases, upto a maximum age of 85 years. This study was conducted according to the guidelines laid down in the Declaration of Helsinki, and all procedures involving human subjects were approved by the Research Ethics Committee of the Queen's University Belfast, Northern Ireland, Clinical Research Ethics Committee of Cork Teaching Hospitals and Research Ethics Committee Board of St. James's Hospital, Dublin. All the subjects provided written informed consent to participate in the study.

\section{Study participants}

Incident cases of histologically confirmed oesophageal adenocarcinoma were identified from electronic pathology records in Northern Ireland and hospital clinical records in the Republic of Ireland. Non-dysplastic long-segment $(\geq 3 \mathrm{~cm})$ Barrett's oesophagus cases were recruited if specialised intestinal metaplasia had been histologically confirmed. Reflux oesophagitis cases had erosions of the oesophageal mucosa diagnosed at endoscopy, classified as grades $2-4$ or grades B, C or D using the Savary-Miller/Hetzel-Dent or Los Angeles methods ${ }^{(37)}$, respectively. Population-based controls were adults with no previous history of Barrett's oesophagus, oesophageal or other gastrointestinal cancer. Randomly selected controls were recruited via the General Practice Master Index in Northern Ireland and from four General Practices in the Republic of Ireland, representing both urban and rural areas within the Dublin and Cork regions. Response rates ranged from $42 \%$ for controls to 69, 82 and $74 \%$ for reflux oesophagitis, Barrett's oesophagus and oesophageal adenocarcinoma cases, respectively.

\section{Data collection}

Trained interviewers collected data from study participants using an electronic questionnaire, which captured information on demographics, lifestyle, medication and co-morbidities. Dietary intake was assessed using a 101-item FFQ, adapted from a version of the European Prospective Investigation into Cancer and Nutrition $\mathrm{FFQ}^{(38)}$, by incorporating additional foods reported as commonly eaten in the North/South Ireland Food Consumption Survey ${ }^{(39)}$. Mean daily dietary intakes were calculated from the FFQ using Q-Builder (Tinuviel Software). Participants were asked to recall their dietary habits over the 12-month period 5 years before interview; BMI 5 years before the interview was calculated using self-reported weight $(\mathrm{kg})$ divided by current height $\left(\mathrm{m}^{2}\right)$, as measured by the interviewer. Helicobacter pylori infection status was assessed from serum samples using a Western blot assay, as previously described ${ }^{(40)}$.

\section{Statistical analysis}

Participants were excluded from the analysis if they failed to complete the FFQ ( $n$ 22) or did not complete the FFQ section on dairy product intake ( $n$ 29), given our interest in studying the relationship between $\mathrm{Mg}$ and $\mathrm{Ca}$ intakes. This left 252 controls, 208 reflux oesophagitis, 212 Barrett's oesophagus and 218 oesophageal adenocarcinoma cases for consideration in the current analysis.

Characteristics and mean nutrient intakes were compared between groups using independent $t$ tests for continuous variables and $\chi^{2}$ tests for categorical variables. Unconditional logistic regression analysis was applied to generate OR and corresponding $95 \%$ CI for oesophageal lesions according to tertiles of intake. Reflux oesophagitis analyses were restricted to controls from Northern Ireland only, as these patients were recruited from Northern Ireland only. Tertiles of energyadjusted nutrient intakes were defined by distribution in the appropriate controls. In order to test for trend, each person within a particular tertile was assigned the median intake value for that tertile before inclusion in the regression model.

The nutrient density method was utilised to adjust for energy intake, which calculates intakes per $4184 \mathrm{~kJ} / \mathrm{d}(1000 \mathrm{kcal} / \mathrm{d})$ in addition to including $\log \mathrm{kJ} / \mathrm{d}(\mathrm{kcal} / \mathrm{d})$ in the regression models ${ }^{(41)}$. Other confounders included in the models were age (years), sex, smoking status (current/previous/never), education (years), BMI 5 years before the interview $\left(\mathrm{kg} / \mathrm{m}^{2}\right)$, occupation (manual/non-manual), alcohol intake $(\mathrm{g} / \mathrm{d})$, regular non-steroidal anti-inflammatory drug use (weekly use for at 
least 6 months duration), H. pylori infection (seronegative/ seropositive) and location (Northern Ireland/Republic of Ireland). We also tested for energy-adjusted intakes of carbohydrate, fat, $\mathrm{Ca}$ and vitamin D, as well as for antioxidant score (a summary of combined intake of vitamin C, vitamin E, total carotenoids and Se, as previously described $\left.{ }^{(42,43)}\right)$. Confounders were selected due to being previously known risk factors for oesophageal lesions within this study population ${ }^{(26,34-36,40,42,44,45)}$. In separate models, we further tested for regular gastro-oesophageal reflux symptoms (ever/never) and hiatus hernia (ever/never), as it is debatable whether reflux symptoms or hiatus hernia may confound or be on the causal pathway between disease risk and the dietary variables of interest. We also sought to adjust for dietary fibre intake; however, it was too highly correlated with $\mathrm{Mg}$ intake $(r 0.58)$ to be included in the statistical models. In an attempt to explore this further, we used the residuals method (regressing energy-adjusted $\mathrm{Mg}$ and fibre intakes) to test for fibre as a potential confounder ${ }^{(41)}$. Further testing for diabetes history, in line with a peer-review suggestion, was also conducted.

Stratified analyses were carried out according to categories of vitamin $\mathrm{D}$ intake and $\mathrm{Ca}: \mathrm{Mg}$ intake ratios. The likelihood-ratio test was applied to evaluate potential interactions in stratified analyses. All the statistical analyses were carried out using Intercooled Stata version 12.0 (StataCorp LP).

\section{Results}

Descriptive characteristics for reflux oesophagitis, Barrett's oesophagus and oesophageal adenocarcinoma cases as well as controls are shown in Table 1. Oesophageal adenocarcinoma cases were more likely to be smokers, consume more alcohol, have a higher BMI, have worked in manual occupations and completed fewer years of education compared with controls (as did Barrett's oesophagus cases). All three case groups were more likely to have experienced gastro-oesophageal reflux symptoms compared with controls.

Daily nutrient intakes of cases and controls are outlined in Table 2. Total energy and energy-adjusted fat intakes were greater across all case groups compared with controls. Energyadjusted carbohydrate, fibre, antioxidant, $\mathrm{Fe}$ and $\mathrm{Mg}$ intakes were lower among all case groups compared with controls. Energy-adjusted $\mathrm{Ca}$ intake was lower in reflux oesophagitis cases only compared with controls, although Barrett's oesophagus and oesophageal adenocarcinoma cases were more likely than controls to have a high Ca:Mg intake ratios (Table 2). There were no significant differences in energy-adjusted vitamin D intakes from foods between case groups and controls.

The association between $\mathrm{Mg}$ intake and disease risk is shown in Table 3. After adjustment for potential confounders, individuals having the highest $\mathrm{Mg}$ intakes from foods had significant reductions in odds of reflux oesophagitis (OR 0.31; $95 \%$ CI 0.11, 0.87) and Barrett's oesophagus (OR 0.29; $95 \%$ CI 0.12, 0.71) compared with individuals having the lowest $\mathrm{Mg}$ intakes. Similarly strong inverse associations were detected for oesophageal adenocarcinoma in baseline models, but these became attenuated after adjustment for further confounders (tertile 3 (T3) $v$. T1; OR $0 \cdot 77 ; 95 \%$ CI $0 \cdot 30,1 \cdot 99$ ). Sensitivity analysis was conducted including further adjustment for gastro-oesophageal reflux symptoms, history of hiatus hernia, history of diabetes and daily fibre, vitamin D and Ca intakes, but these did not markedly alter the magnitude of associations observed (data not shown).

Table 4 displays results from the stratified analysis of $\mathrm{Ca}$ and $\mathrm{Mg}$ intakes according to $\mathrm{Ca}: \mathrm{Mg}$ intake ratios, in relation to reflux oesophagitis, Barrett's oesophagus and oesophageal adenocarcinoma risk. The previously observed protective effect of high $\mathrm{Mg}$ intake was more evident in the context of a low $\mathrm{Ca}: \mathrm{Mg}$ ratio intake for reflux oesophagitis (OR 0.12; $95 \%$ CI 0.02, 0.73) and Barrett's oesophagus (OR 0.24; 95\% CI 0.06, 0.96), although tests for interaction failed to achieve statistical significance $(P=0.13$ and $P=0 \cdot 26$, respectively). Individuals having high $\mathrm{Ca}$ intakes also had reduced odds of reflux oesophagitis and Barrett's oesophagus in the context of a low dietary $\mathrm{Ca}: \mathrm{Mg}$ ratio. Ca:Mg ratio did not alter the null associations between either $\mathrm{Ca}$ or $\mathrm{Mg}$ and oesophageal adenocarcinoma risk (Table 4).

We also investigated the association between disease risk and intakes of $\mathrm{Ca}, \mathrm{Mg}$ and $\mathrm{Ca}: \mathrm{Mg}$ intake ratios according to strata of vitamin $\mathrm{D}$ intakes, although no significant interactions with vitamin D intakes were detected (online Supplementary Table S1). Furthermore, the association between vitamin D intake and risk of reflux oesophagitis, Barrett's oesophagus and oesophageal adenocarcinoma did not differ by strata of $\mathrm{Ca}: \mathrm{Mg}$ intake ratios (online Supplementary Table S2).

\section{Discussion}

In this all-Ireland population-based study, high Mg intake was associated with a reduced risk of reflux oesophagitis and Barrett's oesophagus but not oesophageal adenocarcinoma. The protective effect of $\mathrm{Mg}$ was particularly pronounced in the context of a low Ca:Mg ratio intake. This differential effect also applied to Ca intakes, whereby high Ca intakes were associated with reduced odds of reflux oesophagitis and Barrett's oesophagus in the context of a low $\mathrm{Ca}: \mathrm{Mg}$ intake ratio.

It is unclear why high $\mathrm{Mg}$ intake might particularly influence the earlier stages of cancer development, but not oesophageal adenocarcinoma. Growing evidence indicates that people with insulin resistance, the metabolic syndrome and type 2 diabetes are at high risk of Barrett's oesophagus ${ }^{(46-50)}$. Moreover, inflammation and reactive oxygen species play an important in the aetiology of Barrett's oesophagus ${ }^{(51,52)}$. A number of epidemiological studies have linked low dietary intake of $\mathrm{Mg}$ to elevated risks of systemic inflammation ${ }^{(53,54)}$, insulin resistance ${ }^{(55-59)}$, the metabolic syndrome ${ }^{(60-62)}$ and type 2 diabetes ${ }^{(58,63-67)}$. In addition, Mg deficiency increased oxidative stress ${ }^{(68)}$, whereas $\mathrm{Mg}$ supplementation reduced oxidative stress in animal models ${ }^{(6)}$. Thus, it is biologically plausible that high intakes of $\mathrm{Mg}$ protect against Barrett's oesophagus development.

Furthermore, one striking observation from animal studies is that $\mathrm{Ca}$-adequate and $\mathrm{Mg}$-deficient diets (i.e. diets with higher $\mathrm{Ca}: \mathrm{Mg}$ ratios) led to increase in inflammatory responses and heart lipid peroxidation levels. Conversely, Ca-deficient and Mg-deficient diets (i.e. diets with lower Ca:Mg ratios) caused a significant reduction in heart lipid peroxidation and a normalisation of inflammatory responses ${ }^{(54,69)}$. Thus, these findings 
Magnesium and oesophageal adenocarcinoma risk

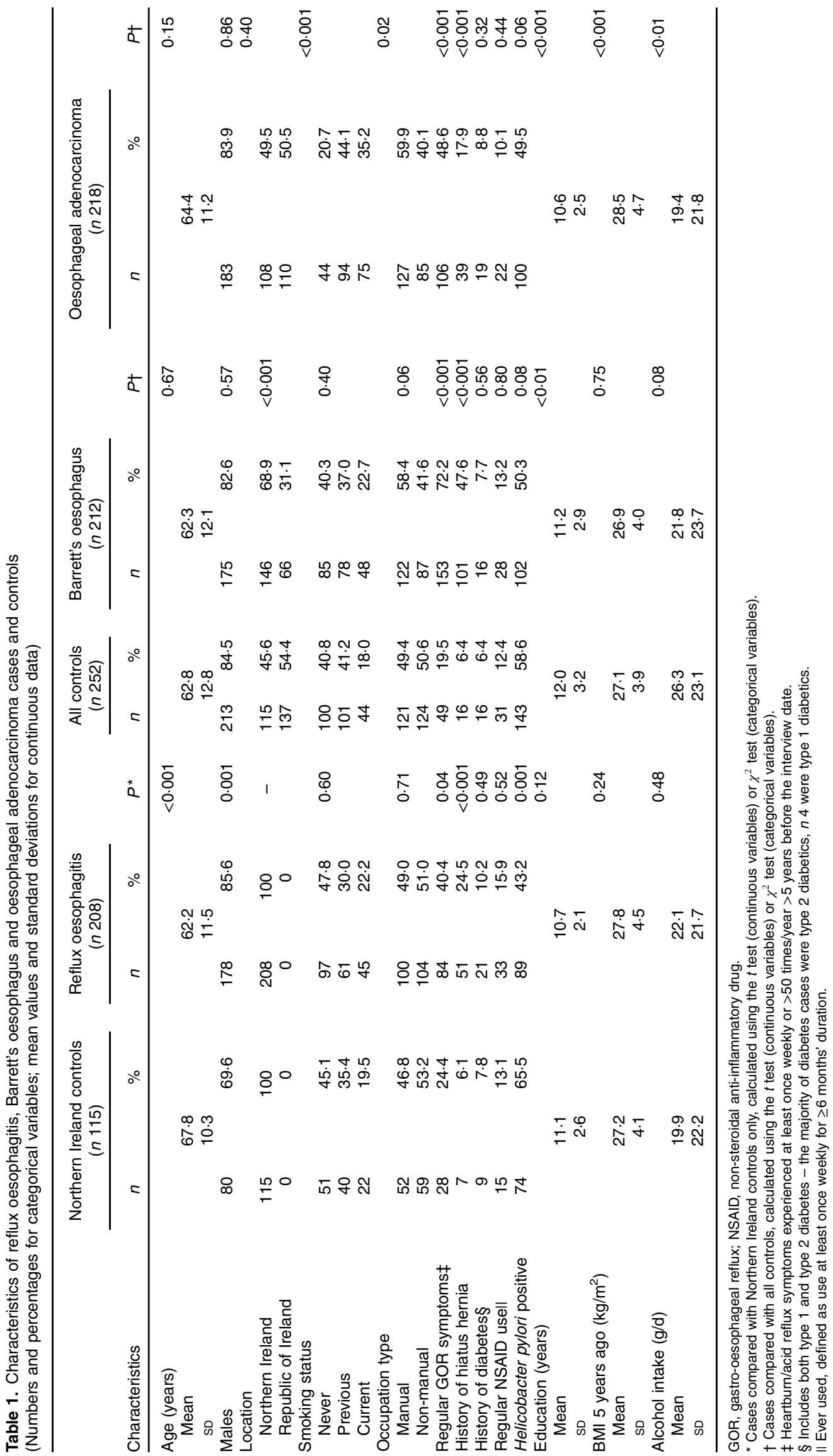




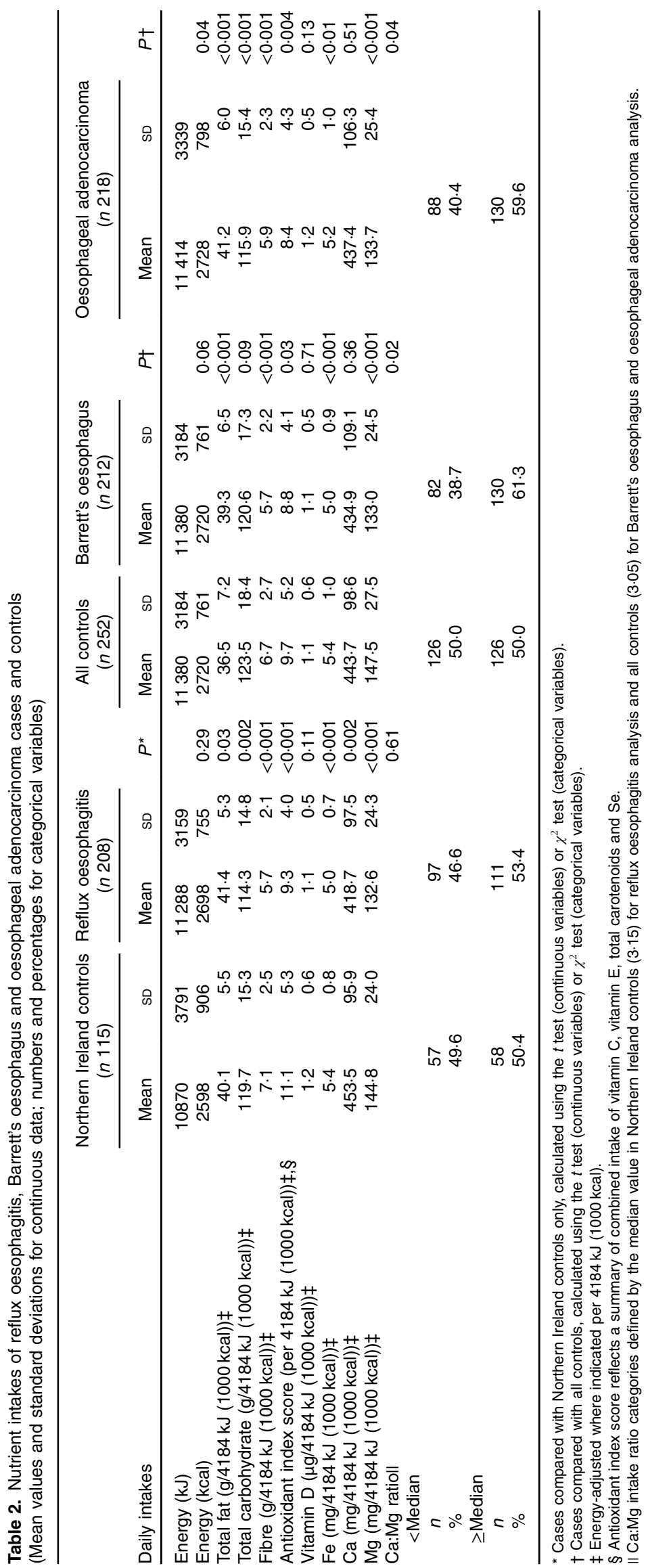


Table 3. Magnesium intake from foods and risk of reflux oesophagitis, Barrett's oesophagus and oesophageal adenocarcinoma (Numbers; odds ratios and $95 \%$ confidence intervals)

\begin{tabular}{|c|c|c|c|c|c|c|c|c|}
\hline & \multirow{2}{*}{$\frac{\text { Controls }}{n}$} & \multirow{2}{*}{$\frac{\text { Cases }}{n}$} & \multicolumn{2}{|c|}{ Model $1^{*}$} & \multicolumn{2}{|c|}{ Model $2 \dagger$} & \multicolumn{2}{|c|}{ Model 3‡ } \\
\hline & & & OR & $95 \% \mathrm{Cl}$ & OR & $95 \% \mathrm{Cl}$ & OR & $95 \% \mathrm{Cl}$ \\
\hline $\begin{array}{l}\text { Reflux oesophagitis } \S \\
\mathrm{Mg}(\mathrm{mg} / 4184 \mathrm{~kJ} \text { per d }(1000 \mathrm{kcal} \text { per } \mathrm{d}))\end{array}$ & 115 & 208 & & & & & & \\
\hline$<130.6$ & 38 & 109 & 1.00 & & 1.00 & & 1.00 & \\
\hline $130 \cdot 6-<155.6$ & 39 & 59 & 0.49 & $0.27,0.89$ & 0.44 & $0.19,1.00$ & 0.44 & $0.18,1.09$ \\
\hline$\geq 155 \cdot 6$ & 38 & 40 & 0.33 & $0.17,0.64$ & 0.28 & $0.11,0.68$ & 0.31 & $0.11,0.87$ \\
\hline $\bar{P}_{\text {trend }}$ & & & & 0.001 & & 0.006 & & 0.03 \\
\hline $\begin{array}{l}\text { Barrett's oesophagus } \\
\text { Mg (mg/4184 kJ per d (1000 kcal per d)) }\end{array}$ & 252 & 212 & & & & & & \\
\hline$<134.0$ & 84 & 109 & 1.00 & & 1.00 & & 1.00 & \\
\hline $134.0<157.7$ & 84 & 70 & 0.66 & $0.42,1.03$ & 0.68 & $0.36,1.26$ & 0.72 & $0.37,1.40$ \\
\hline$\geq 157 \cdot 7$ & 84 & 33 & 0.32 & $0.19,0.54$ & 0.25 & $0.12,0.52$ & 0.29 & $0.12,0.71$ \\
\hline$P_{\text {trend }}$ & & & & $<0.001$ & & $<0.001$ & & 0.008 \\
\hline $\begin{array}{l}\text { Oesophageal adenocarcinoma } \\
\mathrm{Mg}(\mathrm{mg} / 4184 \mathrm{~kJ} \text { per } \mathrm{d}(1000 \mathrm{kcal} \text { per } \mathrm{d}))\end{array}$ & 252 & 218 & & & & & & \\
\hline$<134.0$ & 84 & 121 & 1.00 & & 1.00 & & 1.00 & \\
\hline $134 \cdot 0<157 \cdot 7$ & 84 & 56 & 0.50 & $0.32,0.78$ & 0.69 & $0.39,1.34$ & 0.77 & $0.37,1.61$ \\
\hline$\geq 157 \cdot 7$ & 84 & 41 & 0.37 & $0.22,0.61$ & 0.43 & $0.20,0.92$ & 0.77 & $0.30,1.99$ \\
\hline $\bar{P}_{\text {trend }}$ & & & & $<0.001$ & & 0.03 & & 0.58 \\
\hline
\end{tabular}

* Model 1: adjusted for age (years), sex, energy intake (by nutrient density method + log kJ/d (kcal/d)).

† Model 2: adjusted for model $1+$ smoking status (current/previous/never), BMI 5 years ago, education (years), occupation (manual/non-manual), alcohol (g/d), regular non-steroidal anti-inflammatory drug use (ever/never), Helicobacter pylori infection (seropositive/seronegative) and location (Northern Ireland/Republic of Ireland).

‡ Model 3: adjusted for model 2 + antioxidant index score, energy-adjusted daily intakes of fat $(\mathrm{g} / 4184 \mathrm{~kJ}$ per d $(1000 \mathrm{kcal}$ per d)) and carbohydrate $(\mathrm{g} / 4184 \mathrm{~kJ}$ per d $(1000 \mathrm{kcal}$ per d)).

$\S$ Analysis limited to Northern Ireland controls only.

indicate that in addition to intake of $\mathrm{Mg}$, the $\mathrm{Ca}: \mathrm{Mg}$ intake ratios contribute to the Mg status and, in turn, oxidative stress and inflammation status related to the development of Barrett's oesophagus. One relevant observation is that, although Barrett's oesophagus incidence is increasing, the prevalence rate is much lower in Asian populations ${ }^{(70)}$ who have much lower Ca:Mg ratios compared with their Western counterparts ${ }^{(24)}$.

Interestingly, we also found that high $\mathrm{Ca}$ intake was related to reduced risks of reflux oesophagitis and Barrett's oesophagus when the Ca:Mg intake ratios were below median levels. These findings are consistent with our earlier results on other gastrointestinal pre-malignant diseases, colorectal adenoma ${ }^{(8)}$ and adenoma recurrence ${ }^{(23)}$. On the basis of our previous studies conducted in US populations with high Ca:Mg ratios ${ }^{(8,23)}$ and in Chinese population with a very low Ca:Mg intake ratios ${ }^{(24)}$, it is likely that Ca:Mg ratios between 1.70 and 2.63 may be required for high intake of $\mathrm{Mg}$ or $\mathrm{Ca}$ to be protective against colorectal cancer and $\mathrm{CVD}^{(24)}$. Further studies are warranted to examine whether this is also true for reflux oesophagitis and Barrett's oesophagus.

Adjustment for gastro-oesophageal reflux symptoms did not influence the results shown; therefore, it is unlikely that dietary $\mathrm{Mg}$ and $\mathrm{Ca}$ are mimicking properties of $\mathrm{Ca} / \mathrm{Mg}$-containing antacids in order to reduce the odds of reflux oesophagitis and Barrett's oesophagus. However, little is known about the role of micronutrients in gastro-oesophageal reflux aetiology, and thus this potential mechanism cannot be ruled out.

We have not found a significant association between intake of $\mathrm{Mg}$ and risk for oesophageal adenocarcinoma or a significant interaction between intakes of vitamin D and Mg. Future larger studies are needed. Regarding the interaction with vitamin D, serum concentrations of 25 -hydroxyvitamin D should also be used in future studies, as it is a more accurate biomarker of body vitamin $\mathrm{D}$ status than dietary intake of vitamin $\mathrm{D}$.

This study has several strengths. It is a large population-based study that enabled the role of these dietary factors to be investigated throughout the oesophageal carcinogenesis pathway. Statistical analyses took into consideration a large number of potential confounders. To our knowledge, it is the first study to assess dietary $\mathrm{Mg}$ and $\mathrm{Ca}: \mathrm{Mg}$ ratio in relation to oesophageal lesion risk.

Similar to all case-control studies, there is potential for recall bias due to the use of FFQ to enquire about habitual diet 5 years before interview. Such retrospective questioning of dietary habits is necessary to help overcome the impact of symptoms associated with prevalent disease and resulting changes to eating habits. However, it is unlikely that cases would have differentially reported food sources rich in $\mathrm{Mg}$ due to their diagnoses. The response rate for controls was lower than that observed for cases; however, the daily Mg intake from food in our population-based controls was similar to that estimated in national dietary surveys in Ireland, suggesting that our controls are representative of the general population ${ }^{(71)}$. A further limitation of our study is that we considered only nutrient intake from foods and did not account for supplement usage. However, supplements were estimated to contribute to $<5 \%$ of total mineral intake (with the exception of Fe in females) in adults in the population at this time ${ }^{(71)}$. This may lead to nondifferential misclassification of $\mathrm{Ca}$ and $\mathrm{Mg}$ intakes, which usually biases associations towards the null. Future studies should take supplement usage into account and investigate their contribution to overall mineral intakes in association with risk for these diseases. Owing to the asymptomatic nature of 
Table 4. Calcium and magnesium intake from foods and risk of reflux oesophagitis, Barrett's oesophagus and oesophageal adenocarcinoma, stratified by Ca:Mg intake ratios

(Odds ratios and $95 \%$ confidence intervals)

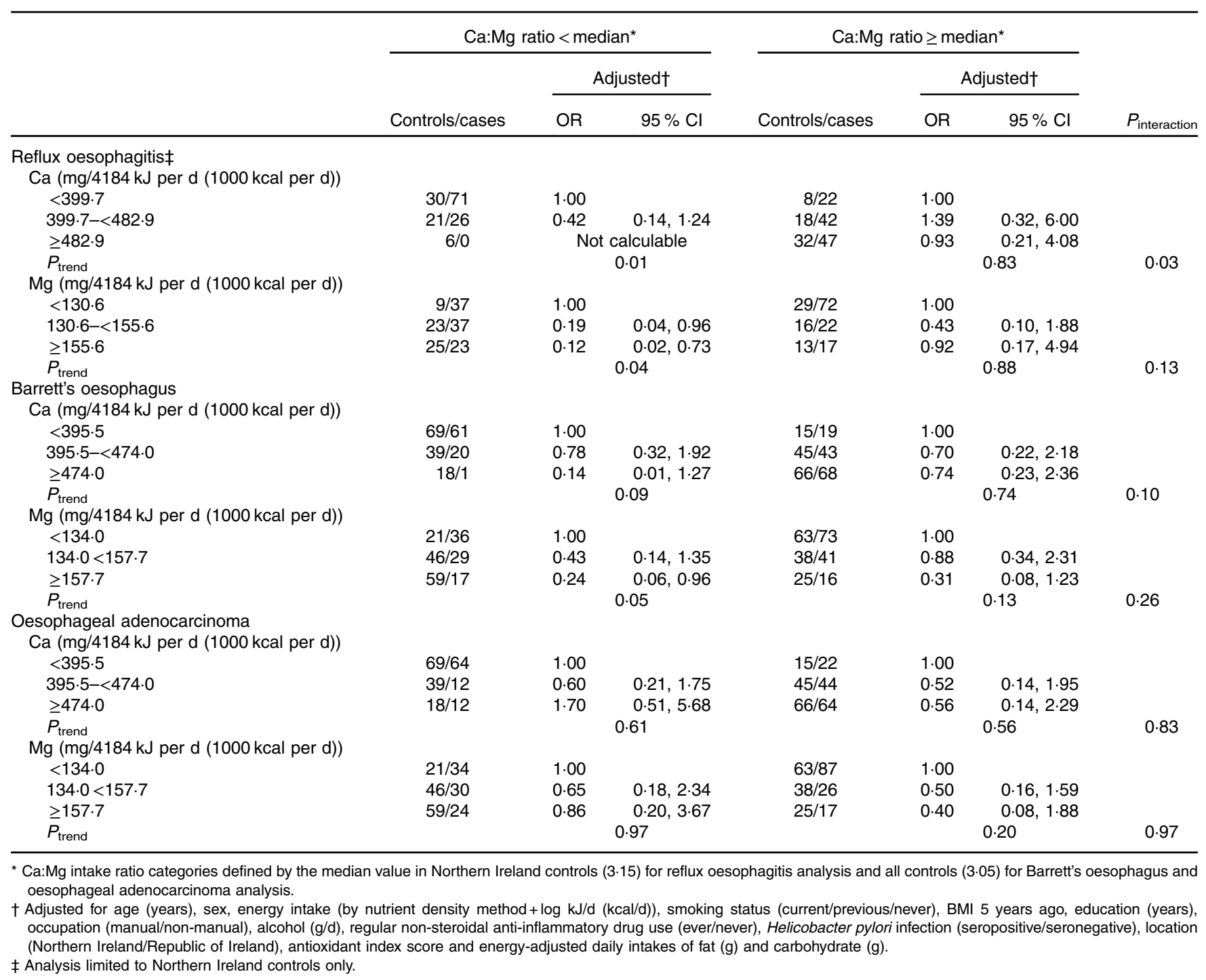

Barrett's oesophagus, and potentially oesophagitis, it is also possible that some of our control population may have had these conditions. Arguably, a superior control population would be individuals who have undergone endoscopy with negative findings; however, such a study design may impact on the generalisability of such controls.

Our findings indicate that high intake of Mg may protect against reflux oesophagitis and Barrett's oesophagus. The protective effect of $\mathrm{Mg}$ may be particularly pronounced in the context of a low $\mathrm{Ca}: \mathrm{Mg}$ ratio intake. This is also true for $\mathrm{Ca}$. Future studies including cohort studies and clinical trials are necessary to confirm our findings. Our findings, if confirmed, will have important public health significance.

\section{Acknowledgements}

The Factors INfluencing the Barrett's Adenocarcinoma Relationship (FINBAR) study group members include L. J. M.
(Queen's University Belfast), L. A. A. (Queen's University Belfast), B. T. Johnston (Belfast Health \& Social Care Trust), R. G. P. Watson (Belfast Health \& Social Care Trust), J. McGuigan (Belfast Health \& Social Care Trust), H. R. Ferguson (Belfast Health \& Social Care Trust), S. J. Murphy (St Vincent's Hospital Dublin), J. V. Reynolds (St James' Hospital, Dublin) and H. Comber (National Cancer Registry of Ireland). The authors appreciate the contributions made by the study participants, their families and all of them who assisted with the study, particularly the Northern Ireland Cancer Registry and National Cancer Registry Cork.

The FINBAR study was supported by funding from Cancer Focus Northern Ireland (formerly the Ulster Cancer Foundation), the Northern Ireland R\&D office and the Health Research Board. H. G. C. is currently supported by a Cancer Research UK Population Research Postdoctoral Fellowship. None of the funders had any role in the design, analysis or writing of this article. 
L. J. M. and L. A. A. designed and conducted the FINBAR study research; Q. D., M. M. C., W. Z. and H. G. C. planned the nutritional and statistical analysis approach; H. G. C. analysed the data; and Q. D. and H. G. C. wrote the first draft of the paper. All the authors read and approved the final version of the manuscript.

The authors have no conflicts of interest to declare.

\section{Supplementary material}

For supplementary material/s referred to in this article, please visit http://dx.doi.org/doi:10.1017/S0007114515004444

\section{References}

1. Flatman PW (1991) Mechanisms of magnesium transport Annu Rev Physiol 53, 259-271.

2. Wester PO (1987) Magnesium. Am J Clin Nutr 45, Suppl. 5, 1305-1312.

3. Saris NE, Mervaala E, Karppanen H, et al. (2000) Magnesium. An update on physiological, clinical and analytical aspects. Clin Chim Acta 294, 1-26.

4. Hartwig A (2001) Role of magnesium in genomic stability. Mutat Res 475, 113-121.

5. Gueux E, Azais-Braesco V, Bussiere L, et al. (1995) Effect of magnesium deficiency on triacylglycerol-rich lipoprotein and tissue susceptibility to peroxidation in relation to vitamin $\mathrm{E}$ content. Br J Nutr 74, 849-856.

6. Hans CP, Chaudhary DP \& Bansal DD (2003) Effect of magnesium supplementation on oxidative stress in alloxanic diabetic rats. Magnes Res 16, 13-19.

7. Institute of Medicine \& Food and Nutrition Board (1997) Dietary Reference Intakes: Calcium, Phosphorus, Magnesium, Vitamin $D$ and Fluoride. Washington, DC: National Academies Press.

8. Dai Q, Shrubsole MJ, Ness RM, et al. (2007) The relation of magnesium and calcium intakes and a genetic polymorphism in the magnesium transporter to colorectal neoplasia risk. Am J Clin Nutr 86, 743-751.

9. Larsson SC, Bergkvist L \& Wolk A (2005) Magnesium intake in relation to risk of colorectal cancer in women. JAMA $\mathbf{2 9 3}$, 86-89.

10. Folsom AR \& Hong CP (2006) Magnesium intake and reduced risk of colon cancer in a prospective study of women. $A m \mathrm{~J}$ Epidemiol 163, 232-235.

11. van den Brandt PA, Smits KM, Goldbohm RA, et al. (2007) Magnesium intake and colorectal cancer risk in the Netherlands Cohort Study. Br J Cancer 96, 510-513.

12. Lin J, Cook NR, Lee IM, et al. (2006) Total magnesium intake and colorectal cancer incidence in women. Cancer Epidemiol Biomarkers Prev 15, 2006-2009.

13. Li K, Kaaks R, Linseisen J, et al. (2011) Dietary calcium and magnesium intake in relation to cancer incidence and mortality in a German prospective cohort (EPIC-Heidelberg). Cancer Causes Control 22, 1375-1382.

14. Wark PA, Lau R, Norat T, et al. (2012) Magnesium intake and colorectal tumor risk: a case-control study and meta-analysis. Am J Clin Nutr 96, 622-631.

15. Norman DA, Fordtran JS, Brinkley LJ, et al. (1981) Jejunal and ileal adaptation to alterations in dietary calcium: changes in calcium and magnesium absorption and pathogenetic role of parathyroid hormone and 1,25-dihydroxyvitamin D. J Clin Invest 67, 1599-1603.
16. Hardwick LL, Jones MR, Brautbar N, et al. (1991) Magnesium absorption: mechanisms and the influence of vitamin D, calcium and phosphate. J Nutr 121, 13-23.

17. Domrongkitchaiporn S, Ongphiphadhanakul B, Stitchantrakul W, et al. (2000) Risk of calcium oxalate nephrolithiasis after calcium or combined calcium and calcitriol supplementation in postmenopausal women. Osteoporos Int 11, 486-492.

18. Green JH, Booth C \& Bunning R (2003) Acute effect of high-calcium milk with or without additional magnesium, or calcium phosphate on parathyroid hormone and biochemical markers of bone resorption. Eur J Clin Nutr 57, 61-68.

19. Nielsen FH, Milne DB, Gallagher S, et al. (2007) Moderate magnesium deprivation results in calcium retention and altered potassium and phosphorus excretion by postmenopausal women. Magnes Res 20, 19-31.

20. Hoenderop JG \& Bindels RJ (2005) Epithelial $\mathrm{Ca}^{2+}$ and $\mathrm{Mg}^{2+}$ channels in health and disease. I Am Soc Nephrol 16 , $15-26$.

21. Karkkainen MU, Wiersma JW \& Lamberg-Allardt CJ (1997) Postprandial parathyroid hormone response to four calciumrich foodstuffs. Am J Clin Nutr 65, 1726-1730.

22. Abrams SA, Grusak MA, Stuff J, et al. (1997) Calcium and magnesium balance in 9-14-y-old children. Am J Clin Nutr 66 , 1172-1177.

23. Dai Q, Sandler R, Barry E, et al. (2012) Calcium, magnesium, and colorectal cancer. Epidemiology 23, 504-505.

24. Dai Q, Shu XO, Deng X, et al. (2013) Modifying effect of calcium/magnesium intake ratio and mortality: a populationbased cohort study. BMJ Open 3, e002111.

25. Deng X, Song Y, Manson JE, et al. (2013) Magnesium, vitamin D status and mortality: results from US National Health and Nutrition Examination Survey (NHANES) 2001 to 2006 and NHANES III. BMC Med 11, 187.

26. Mulholland HG, Murray LJ, Anderson LA, et al. (2011) Vitamin $\mathrm{D}$, calcium and dairy intake, and risk of oesophageal adenocarcinoma and its precursor conditions. Br J Nutr 106, 732-741.

27. Edgren G, Adami HO, Weiderpass E, et al. (2013) A global assessment of the oesophageal adenocarcinoma epidemic. Gut 62, 1406-1414.

28. Bosetti C, Levi F, Ferlay J, et al. (2008) Trends in oesophageal cancer incidence and mortality in Europe. Int J Cancer 122, $1118-1129$

29. El-Serag HB, Sweet S, Winchester CC, et al. (2014) Update on the epidemiology of gastro-oesophageal reflux disease: a systematic review. Gut 63, 871-880.

30. Ferlay J, Soerjomataram I, Dikshit R, et al. (2015) Cancer incidence and mortality worldwide: sources, methods and major patterns in GLOBOCAN 2012. Int J Cancer 136, E359-E386.

31. Alexandropoulou K, van Vlymen J, Reid F, et al. (2013) Temporal trends of Barrett's oesophagus and gastrooesophageal reflux and related oesophageal cancer over a 10-year period in England and Wales and associated proton pump inhibitor and H2RA prescriptions: a GPRD study. EurJ Gastroenterol Hepatol 25, 15-21.

32. Luk CP, Parsons R, Lee YP, et al. (2013) Proton pump inhibitor-associated hypomagnesemia: what do FDA data tell us? Ann Pharmacother 47, 773-780.

33. Markovits N, Loebstein R, Halkin H, et al. (2014) The association of proton pump inhibitors and hypomagnesemia in the community setting. J Clin Pharmacol 54, 889-895.

34. Anderson LA, Johnston BT, Watson RG, et al. (2006) Nonsteroidal anti-inflammatory drugs and the esophageal inflammation-metaplasia-adenocarcinoma sequence. Cancer Res 66, 4975-4982. 
35. Anderson LA, Watson RG, Murphy SJ, et al. (2007) Risk factors for Barrett's oesophagus and oesophageal adenocarcinoma: results from the FINBAR study. World J Gastroenterol 13, $1585-1594$.

36. Mulholland HG, Cantwell MM, Anderson LA, et al. (2009) Glycemic index, carbohydrate and fiber intakes and risk of reflux esophagitis, Barrett's esophagus, and esophageal adenocarcinoma. Cancer Causes Control 20, 279-288.

37. Nayar DS \& Vaezi MF (2004) Classifications of esophagitis: who needs them? Gastrointest Endosc 60, 253-257.

38. Day N, Oakes S, Luben R, et al. (1999) EPIC-Norfolk: study design and characteristics of the cohort. European Prospective Investigation of Cancer. Br J Cancer 80, Suppl. 1, 95-103.

39. Harrington KE, Robson PJ, Kiely M, et al. (2001) The North/ South Ireland Food Consumption Survey: survey design and methodology. Public Health Nutr 4, 1037-1042.

40. Anderson LA, Murphy SJ, Johnston BT, et al. (2008) Relationship between Helicobacter pylori infection and gastric atrophy and the stages of the oesophageal inflammation, metaplasia, adenocarcinoma sequence: results from the FINBAR case-control study. Gut 57, 734-739.

41. Willett W \& Stampfer MJ (1986) Total energy intake: implications for epidemiologic analyses. Am J Epidemiol 124, $17-27$.

42. Murphy SJ, Anderson LA, Ferguson HR, et al. (2010) Dietary antioxidant and mineral intake in humans is associated with reduced risk of esophageal adenocarcinoma but not reflux esophagitis or Barrett's esophagus. J Nutr 140, $1757-1763$.

43. Kubo A, Levin TR, Block G, et al. (2008) Dietary antioxidants, fruits, and vegetables and the risk of Barrett's esophagus. Am J Gastroenterol 103, 1614-1623.

44. Anderson LA, Cantwell MM, Watson RG, et al. (2009) The association between alcohol and reflux esophagitis, Barrett's esophagus, and esophageal adenocarcinoma. Gastroenterology 136, 799-805.

45. O'Doherty MG, Cantwell MM, Murray LJ, et al. (2011) Dietary fat and meat intakes and risk of reflux esophagitis, Barrett's esophagus and esophageal adenocarcinoma. Int $J$ Cancer 129, 1493-1502.

46. Rubenstein JH, Morgenstern H, McConell D, et al. (2013) Associations of diabetes mellitus, insulin, leptin, and ghrelin with gastroesophageal reflux and Barrett's esophagus. Gastroenterology 145, 1237-1244 e1-5.

47. Ryan AM, Healy LA, Power DG, et al. (2008) Barrett esophagus: prevalence of central adiposity, metabolic syndrome, and a proinflammatory state. Ann Surg 247, 909-915.

48. Fujita T (2009) Modifiable factors related to Barrett esophagus. Ann Surg 249, 352-353.

49. Leggett CL, Nelsen EM, Tian J, et al. (2013) Metabolic syndrome as a risk factor for Barrett esophagus: a populationbased case-control study. Mayo Clin Proc 88, 157-165.

50. Iyer PG, Borah BJ, Heien HC, et al. (2013) Association of Barrett's esophagus with type II diabetes mellitus: results from a large population-based case-control study. Clin Gastroenterol Hepatol 11, 1108-1114 e5.

51. Nelsen EM, Kirihara Y, Takahashi N, et al. (2012) Distribution of body fat and its influence on esophageal inflammation and dysplasia in patients with Barrett's esophagus. Clin Gastroenterol Hepatol 10, 728-734.
52. Poehlmann A, Kuester D, Malfertheiner P, et al. (2012) Inflammation and Barrett's carcinogenesis. Patbol Res Pract 208, 269-280.

53. Dibaba DT, Xun P \& He K (2014) Dietary magnesium intake is inversely associated with serum C-reactive protein levels: metaanalysis and systematic review. Eur J Clin Nutr 68, 510-516.

54. Ziegler D (2005) Type 2 diabetes as an inflammatory cardiovascular disorder. Curr Mol Med 5, 309-322.

55. Paolisso G, Sgambato S, Gambardella A, et al. (1992) Daily magnesium supplements improve glucose handling in elderly subjects. Am J Clin Nutr 55, 1161-1167.

56. Paolisso G, Sgambato S, Pizza G, et al. (1989) Improved insulin response and action by chronic magnesium administration in aged NIDDM subjects. Diabetes Care 12, 265-269.

57. Fung TT, Manson JE, Solomon CG, et al. (2003) The association between magnesium intake and fasting insulin concentration in healthy middle-aged women. $J$ Am Coll Nutr 22, 533-538.

58. Song Y, Manson JE, Buring JE, et al. (2004) Dietary magnesium intake in relation to plasma insulin levels and risk of type 2 diabetes in women. Diabetes Care 27, 59-65.

59. Guerrero-Romero F, Tamez-Perez HE, Gonzalez-Gonzalez G, et al. (2004) Oral magnesium supplementation improves insulin sensitivity in non-diabetic subjects with insulin resistance. A double-blind placebo-controlled randomized trial. Diabetes Metab 30, 253-258.

60. Champagne CM (2008) Magnesium in hypertension, cardiovascular disease, metabolic syndrome, and other conditions: a review. Nutr Clin Pract 23, 142-151.

61. He K, Liu K, Daviglus ML, et al. (2006) Magnesium intake and incidence of metabolic syndrome among young adults. Circulation 113, 1675-1682.

62. He K, Song Y, Belin RJ, et al. (2006) Magnesium intake and the metabolic syndrome: epidemiologic evidence to date. J Cardiometab Syndr 1, 351-355.

63. Dong JY, Xun P, He K, et al. (2011) Magnesium intake and risk of type 2 diabetes: meta-analysis of prospective cohort studies. Diabetes Care 34, 2116-2122.

64. Colditz GA, Manson JE, Stampfer MJ, et al. (1992) Diet and risk of clinical diabetes in women. Am J Clin Nutr 55 , 1018-1023

65. Lopez-Ridaura R, Willett WC, Rimm EB, et al. (2004) Magnesium intake and risk of type 2 diabetes in men and women. Diabetes Care 27, 134-140.

66. Larsson SC \& Wolk A (2007) Magnesium intake and risk of type 2 diabetes: a meta-analysis. J Intern Med 262, 208-214.

67. Schulze MB, Schulz M, Heidemann C, et al. (2007) Fiber and magnesium intake and incidence of type 2 diabetes: a prospective study and meta-analysis. Arch Intern Med 167, 956-965.

68. Hans CP, Chaudhary DP \& Bansal DD (2002) Magnesium deficiency increases oxidative stress in rats. Indian J Exp Biol 40, 1275-1279.

69. Bussiere FI, Gueux E, Rock E, et al. (2002) Protective effect of calcium deficiency on the inflammatory response in magnesium-deficient rats. Eur J Nutr 41, 197-202.

70. Lee HS \& Jeon SW (2014) Barrett esophagus in Asia: same disease with different pattern. Clin Endosc 47, 15-22.

71. Hannon EM, Kiely M, Harrington KE, et al. (2001) The North/ South Ireland Food Consumption Survey: mineral intakes in 18-64-year-old adults. Public Health Nutr 4, 1081-1088. 